\title{
BIOPESTICIDES: EFFECTIVE ALTERNATIVE TO ORGANIC NEPAL
}

\author{
Yubak Dhoj G. C., PhD
}

\begin{abstract}
Historically agriculture has been the major -culture to the majority of the Nepalese people, however, in recent days, the trend is gradually shifting towards other sectors like business and services. The dependency on agriculture both on direct and indirect has been declining from $90 \%$ to $65 \%$ indicating towards its specialization, commercialization and diversification. This has further necessitated to the high input based agriculture, especially chemical fertilizers, pesticides and seeds. At the same time, considerable interests are pounding on the organic agriculture. This fact has becoming evident due to growing demands of organic produce within and outside the country. Nepal can earn money by producing and exporting of organic agricultural produce to its neighboring countries- China and India. In this context, Nepal is situated on the strategic point where it may take the advantages from the flourishing economy of its giant neighbors. Nepal can choose natural farming as well to rely on the use of biorational compounds like biopesticides for combating biotic and abiotic stresses. Very importantly, such products need producing within the home country and are made accessible to the farmers.
\end{abstract}

Key words: Biopesticides, Biotic stresses, Biorational compounds, Chemical pesticides, Fertilizers, Producers

\section{INTRODUCTION}

Chemical pesticides are substances used to control pests that are associated with agricultural crops. This includes fungicides, herbicides, miticides or acaricides, nematicides, rodenticides, avicides, mulluscicides, fumigants etc. Only few of the pesticides are plant origin and most of them are made with minerals and other elements. Modern use of chemical pesticides dates back to 1867, when Paris Green was first used to manage Colorado potato beetle. After that, various inorganic or plant originated pesticides came into existence. The successful discovery of the use of dichloro-diphenyltrichloroethane (DDT) by the Swiss scientist Paul Hermann Müller in 1939 opened the floodgates worldwide for more and more pesticide synthesis and use, especially for the control of agricultural pests and vector-borne diseases. In Nepal, DDT and pyrethrum were use in 1950 from USA exclusively for Malaria control for Gandaki Hydropower Project. Subsequently, in November 1952, DDT became the chemical pesticide to be introduced in Nepal by Ministry of Health / the then His Majesty's Government of Nepal. This marked the introduction of pesticides in Nepal (Thapa, 1997, FAO, 2001). Not only this but also in 1955, Paris green, Gammexene and nicotine sulfates were imported for the same purpose of eradicating malaria. These pesticides were mostly provided by US Agency for International

\footnotetext{
${ }^{1}$ Director General, Department of Agriculture Email:yubakgc@yahoo.com
} 
Development (USAID), which sponsored programs through grant assistance primarily for the control of vector-borne diseases. Since then, the use of pesticides as plant protection materials has steadily increased, with the introduction of high yielding varieties of rice, maize, wheat and vegetables which led to the formation of the Agriculture Inputs Corporation in 1967 to deal with agricultural inputs including pesticides. Nepal has a history of using chemical fertilizers and pesticides for more than forty years for higher agriculture production yields. The different groups of pesticides introduced in Nepal in different periods are: Organochlorines- 1950s; Organophosphates - 1960s, Carbamates1970s, Synthetic pyrethoids- 1980s. The use of chemical provides instant benefits but in long run these chemicals destroy the production capacity of the soil. They also leave negative impact on the life of the human beings, and lead to other environmental problems too. They often lead to breaking down of the resistance of the pests against the toxicity of the pesticides leading to pest outbreak, resistance and resurgence. Such realization gave birth to the concept of Integrated Pest Management (IPM) in 1990s with increasing emphasis of biopesticides. However, in Nepal, search of biopesticides has been the recent practices roughly after 2000. In support of Department of Agriculture through Plant Protection Directorate, Metarhizium anisopliae and Trichoderma viridae were started formulating in the private sectors for the first time in Nepal (GC et al., 2008).

Most pesticides that are used in Nepal are broad spectrum in nature, which pose the effects both target and non-target organisms. Fewer of the compounds are safer, but their use has been extremely limited because of the farmers' choice. General tendencies of choosing chemical pesticides in Nepal are based on their knock down effects as higher the rate of killing better their values and vice versa. Majority of the farmers are unaware of pesticide types, dose, frequencies and waiting periods and safer disposals. The resultant effects on human health include cancer, birth defects, reproductive problems, tumors and damage of liver, kidney and neural organs. To prevent such hazards, Nepal has also banned 16 pesticides including PIC (Prior Informed Consent) listed pesticides (Methyl Parathion and Monocrotophos) in the country. Highly persistent types (POP pesticides), Phosphamidon and Organo-mercury fungicides, organochlorine including endosulfan and others some hazardous chemical pesticides have been banned in the country (PRMS, 2013). However, because of an open and porous border with India, there is a considerable, but unknown quantity of trade between farmers close to the border. Hence, illicit/illegal import of pesticides issue needs to be addressed in multilateral approach with neighboring countries to prevent potential infiltration of banned/ unregistered pesticides (Palikhe, 2005).

\section{OBJECTIVE}

- To explore the national scenario of organic agriculture and importance of biopesticides in organic farming

- To aware the use of chemical pesticides in agriculture and their consequences 


\section{NATIONAL SCENARIO}

Every government in Nepal has been considering that agricultural development is in top priority, but the export situation is not that encouraging. Looking into the agro-ecological potentiality, Nepal can pursue agricultural development through the adoption of organic agriculture. Yet, Nepal has added advantages of adopting organic agriculture because of its organic nature of production and readily available markets in neighboring countries, the China and India. Organic agriculture systems promote the environmentally, socially and economically sound production of crops with respect to the natural capacity of plants and local conditions (Sharma, 2005). It aims to optimize quality production and is an emerging area, so this is the right time to begin organic agriculture in Nepal. Since there are various places in Nepal which is still beyond the reach of these chemical inputs due to lack of transportation facility. So we have still time to aware them of the situation and stop using such chemical inputs. Because of this, farmers of Nepal are still far from all the negative environmental effects of the inorganic method. For a country bestowed by nature with tremendous organic agricultural potentiality, this must be the right choice; however, it has not been able to harness it properly. Considering the level of awareness and scale of production, Nepal is still at infant stage for the promotion of organic agriculture. The promotion of inorganic farming techniques causes the deterioration of soil condition as well as it causes the undesirable effects. The chemicals decrease the quality of our food which is evident in the case of rapid loss of rice flavor as a result of excessive use of chemical fertilizers. What is missing today is the lack of availability of organic inputs such as organic fertilizer and biopesticides in one hand and also authentication of Nepalese niche products through certification. Market for organic produce is quite rudimentary and legal certification hasn't started. Most of the organic production and marketing system in Nepal is on the basis of community trust. In many cases, organic certification has becoming out of reach of majority of farmers. There has been lacuna in research on the technologies to support organic agriculture.

In the name of commercial farming, there has been rampant application of in-organic inputs, which is not only hazardous to both human life and the environment but also hinders in exports. Soil fertility is degrading day by day, and people are suffering with critical diseases even up to cancers due to the use of pesticide contaminated foods. If we do not become timely conscious and create awareness, the situation will be beyond our control, and become a great threat to our country. Necessary steps must be taken towards the institutionalization of organic farming in Nepal. Our initiative actions in this regard can be recognition for the future generations.

Along with the commercialization and knockdown effects, usages of chemicals have increased dramatically in recent decades. Even though the average fertilizer and pesticides 
consumption in Nepal is very low ( $26 \mathrm{~kg}$ and $396 \mathrm{gm}$ a.i. per hectare respectively) but injudicious use is widespread especially in commercial area (Thapa, 1997; PPD, 2014). Some of the areas like Panchkhal are the living example with the consequences of mishandling and overuse of chemical pesticides where the people are suffering from skin irritation, headache, nausea, and the cases of skin cancer. The ignorance and awareness among the rural people leads to present consequences. Their usages have been concentrated mainly in cash crops destined for export, or the local market: particularly tea, vegetables, rice, cotton, bananas and several other crops. Unfortunately the regulation of pesticide trade and use and the ability of small-scale farmers to use the products effectively and safely have lagged behind. This is grossly lacking due to unavailability of effective alternative pest control compounds in Nepal. There is great influence of the multinational companies to promote chemical pesticides as numerous companies are involved in this business. Farmers are tempted by higher returns using chemicals, and feel the higher price of organic products does not offset the lower yield. Pesticides related problems in Nepal are difficult to notice except poisoning cases which however, may have posed long term effects to the non-target organisms, environments and human-beings. The result is often environmental contamination, severe health problems and un-profitable crop production. Pesticide misuse has been evident at many levels starting from import, storage, usages, waiting periods and handling of the empty containers. In majority cases, waiting periods are seldom considered. Fishing, dipping vegetables like tomato and brinjal and other crops are some of the obvious malpractices. Use of sub-standard and date expired pesticides with low public awareness are some of the common phenomenon in the inaccessible areas of Nepal. In general, systematic studies are lacking to monitor the undesirable side effects. Department of Agriculture through the involvement of Plant Protection Directorate has initiated Rapid Bioassay for Pesticide Residue (RBPR) facility in one of the market hobs of vegetables in Kathmandu (PPD, 2014). It has revealed that, some of the vegetables produced in some pocket areas possess pesticide residues excessively indicating the urgent needs of interventions, like organic agriculture.

\section{METHODOLOGY}

A lot of research articles related to the use of chemicals for the control of agricultural pests, production and use of chemical pesticides in different era , situation of organic farming, importance and use of biopesticides for pest management were reviewed. Information and feedback of biopesticides for the control of agricultural pests management in organic farming and consequences of chemical pesticides were gathered by interaction with the farmers, field visits, seminars and meetings. So, the paper is prepared based on documented materials and synthesis of experiences. 


\section{IMPORTANCE OF BIOPESTICIDES IN ORGANIC AGRICULTURE}

Organic agriculture is more suited to the small holding farmers where majority of the farmers in Nepal owns less than a hectare of land. Organic produce not only contributes to the GDP but also helps in reducing the poverty through securing income. Organic agriculture is often inexpensive and easier for small farmers; it is not only because of price premiums, but also because of lower production costs. The technologies adopted in organic agriculture can decrease the costs of production as chemical inputs are substituted by locally available and cheaper organic inputs. There are substantial evidences of enhancing profitability and income of poor farmers through diversifying of the products. In order to create the awareness on organic movement, capacity building coupled with availability of organic inputs is important aspects. Hence, it has not been delay of the development of organic agriculture in the country. As a result, Government of Nepal has encouraged organic producers and exporters through subsidized program. Some of the Government laboratories as well as private industry have initiated biopesticide productions with their own efforts. Despite of the Government emphasis, organic movement has not been moving to the desired level in Nepal. Several reasons are associated for this. Government has made available chemical fertilizers on subsidized rate as well as supported for the organic fertilizer producers with some seed money however, not on the organic pesticide production. Considerable level of awareness and interest has been arisen among the producers, consumers and policy makers about the organic produce but the production is still below than $5 \%$. Yet, it has to be widely realized that inorganic pesticides are more poisonous compared to fertilizers. Hence, increasing emphasis has to be given on the production and utilization of organic pesticides. Similarly, certification system of organic products is often cumbersome and expensive. This can be made accessible and easier by providing the subsidy and also by rendering the services in the field level. It should also formulate a policy in regards to organic agricultural development, so that Nepal can gradually become an organic country.

Elsewhere, agricultural sector is impacted by climate change and such impacts are seldom considered in a country like Nepal because of the poor research backups. Nepal's vulnerability in the agriculture sector is related to water, drought, floods etc. Commercial farming is heavily dependent on external inputs such as chemical pesticides and fertilizers. Such practices often invite undesirable results such as outbreak of insect pests and diseases as soil and water pollution. In some way, these issues can be well addressed through organic agricultural systems which can help to reduce agricultural GHG emissions through energy conservation, lower levels of carbon-based inputs, lower use of synthetic fertilizer and pesticides, and other features that minimize GHG emissions and sequester carbon in the soil. As soil is a major store of carbon, if organic agricultural systems are adopted overall soil quality can be improved. Scientific evidences suggest that widespread adoption of organic farming practices would offset $23 \%$ of greenhouse gas emissions from agriculture 
through soil carbon sequestration alone. The result is that agricultural soils have the capacity to take up carbon through roots, litter, harvest residues, and animal manures used in agricultural production. Similarly, use of biopesticides avoids the need of deadly poisonous chemical compounds from the plants and agricultural fields. The off-season production of vegetables and other numerous products can be exported if they are less contaminated with chemicals.

The demand of organic agriculture is increasing both in the internal as well as external markets (Ramesh et al., 2005). It is estimated that about $5 \%$ of households of urban areas are consuming organic products and almost $50 \%$ are found to have desire in Nepal. Most of the farmers are well aware about the negative repercussion of the indiscriminate use of the agro-chemicals in their farm and opined that they would like to shift from inorganic towards organic agriculture; however, availability of production inputs like biopesticides and marketing for such products is the greatest bottleneck. Biopesticides are certain types of pesticides derived from such natural materials as animals, plants, bacteria, and certain minerals. Microbial pesticides consist of a microorganism (e.g., a bacterium, fungus, virus or protozoan) as the active ingredient. Microbial pesticides can control many different kinds of pests, although each separate active ingredient is relatively specific for its target pest. For example, there is insect pathogenic fungus, Metarhizium anisopliae, which is effective to the ranges of insects (GC and Keller, 2005). Its production has been initiated with the local strains of Nepal. It avoids the need of synthetic pesticides. Bacteria based $\mathrm{Bt}$, Nuclear polyhederosis virus and protozoan parasitoids are other bioagents, whose formulations are available in different forms. Trichoderma is another useful biofungicides. They can be used against diseases. Biopesticides are usually inherently less toxic than conventional pesticides. Biopesticides generally affect only the target pest and closely related organisms, in contrast to broad spectrum, conventional pesticides that may affect organisms as different as birds, insects, and mammals. Biopesticides often are effective in very small quantities and often decompose quickly, thereby resulting in lower exposures and largely avoiding the pollution problems caused by conventional pesticides. When used as a component of Integrated Pest Management (IPM) programs, biopesticides can greatly decrease the use of conventional pesticides, without decreasing crop yields. To use biopesticides effectively, however, users need to know a great deal about managing pests.

In this situation strengthening of awareness and import control would hardly accomplish the goal of organic Nepal. Since Nepal needs increasing its agriculture production to meet the demands of increasing population as well as to extend its niche markets in the international level. Support system be institutionalized and strengthened from seeds, fertilizers, biopesticdies, market promotion through certification and export. All domestic organics reach to consumers without labeling. Consumers have a belief that organic food is healthier, less polluted and more natural, than conventionally produced foods. Many of the 
consumers are of the view that quality of the organic products is good and that's why these products are expensive. Geographically, Nepal lies in very strategic positions for marketing organic products to its giant neighbors, the China in the North and India in rests of the areas. Nearly half of the world's population lies in these countries indicating greatest demand of such foods. The economy of these countries is rising and very vibrant and large number of people is demanding such foods. Nepal can alter its shifts and utilize its niche products in making economy robust.

\section{FINDING AND CONCLUSION}

There has been growing interests in organic agriculture in developing countries because of the availability of natural inputs as well as human resources. Also it is due to its wider variability in agro-climates. Nepal can use traditional and indigenous farming practices and knowledge because of its small production units. It manages and enhances diversity, to incorporate biological principles and resources into farming systems, and to ecologically intensify agricultural production. This leads to an increased engagement in farming which can trigger greater opportunities for rural employment and economic upliftment. Thus through greater emphasis on use of local resources contributes to the empowerment of farmers and local communities. It has very rich botanical diversity, which can also be utilized both in the form of organic manure and pesticides

Similarly, the use of household and municipal wastes offers greater potentiality to be transformed to produce nitrogenous based fertilizer equivalent numerous ton of urea. The poultry litter can also be used in place of inorganic fertilizers. Both of these wastes in Nepal are estimated to represent only $10 \%$ of the total organic waste available for the recycling in Nepal. Other large sources of organic wastes in the country are diary, cattle, sheep, goat, piggery, aquaculture, meat and fish processing which are also useful in the farming. If all these wastes are completely recycled, the country can potentially recover and recycle the organic waste to replace the inorganic fertilizer.

Bio-fertilizer, microbial fertilizer, and conservation of soil and symbiosis will be able to generate another $25 \%$, making the organic options for fertilizer available in the country provided the technologies for organic fertilizer are well developed and commercialized (Veeresh, 1999). Rapidly growing food markets in domestic market, and half of the world population in the vicinity of Nepal, it can be a food bowl for safer food. Many report suggests, Indian organic food market has begun growing rapidly. With a population of over 1.3 billion, China has emerged as the world's largest consumer market for food and beverage (F\&B), surpassing the United States in 2011. According to a recent study conducted by the Economist, China is the second fastest growing F\&B market out of all major Asian countries, with an average annual growth rate of $30 \%$ in the past five years, according to the Ministry of Commerce. Way out for export oriented agriculture should 
focus on safer food market opportunities that exist in India and China and Nepal has comparative advantage for it due to its very diverse agro-ecology, and proximity to world's largest and growing organic food markets. Nepal can move ahead in this endeavor with capitalizing alternative bio-pesticides, fertilizer, crop varieties, and organic crop production techniques/technologies. For this purpose, a starting point can be alternative pesticides that are being developed in Nepal that can support for organic crop production. Nepal's rich biodiversity of local germpalsm along with its wider networks also provide an access for selection of crop varieties that are resistant/tolerant to major diseases and pests. Some agricultural areas in Nepal (in hills and mountains) have never used chemical fertilizers and pesticides for farming and by default these areas can well support the organic farming. The shift to inorganic in many areas are not very long, hence there is significant local and indigenous knowledge system still available for organic crop management. In order to move forward formation of a task force members consisting of cross section of experts, Government agencies, export agencies, processing/manufacturing industries, NGO, Universities, etc. can be involved.

\section{REFERENCES}

FAO, 2001. World markets for organic fruit and vegetables - Opportunities for developing countries in production and export of organic horticultural products. International Trade Centre (ITC) Technical Centre for Agriculture and Rural Cooperation, Food and agriculture Organization of the United Nations (FAO), Rome.

G. C., Y. D. and Keller, S., 2005. Metarhizium anisopliae for white grub control in Nepal. Insect Pathogens and Insect Parasitic Nematodes: Melolontha IOBC/ wprs Bulletin vol. 28 (2) 2005, pp 57-61.

G. C., Y. D., Keller, S., Nagel, P. and Kafle, L. N., 2008. Virulence of Metarhizium anisopliae and Beauveria bassiana against common white grubs in Nepal. Formosan Entomol. 28: 11-20.

Palikhe, B. R., 2005. Pesticide Management in Nepal: In view of code of conduct. Paper presented at the regional workshop on international code of conduct on the distribution and use of pesticides: Implementation, monitoring and observance, Bangkok, Thailand.

PPD, 2014. Annual Progress Report. Plant Protection Directorate, Hariharbhawan, Lalitpur, Nepal.

PRMS, 2013. List of registered pesticides. Pesticide Registration and Management Section, Plant Protection Directorate, Hariharbhawan, Lalitpur, Nepal.

Ramesh, P., M. Singh and A. Subba Rao, 2005. Organic farming: Its relevance to the Indian Contex. Current Science, 88(4):33-40.

Sharma, G., 2005. Organic Agriculture in Nepal: An Analysis in to Status, Policy, Technology and Psychology." In: Sharma, G. and P.B. Thapa (Eds.) Proceeding of National Workshop on Organic Agriculture and Food Security, December 13-15, 2005, Kathmandu, Nepal.

Thapa, R. B., 1997. An overview of pesticides pollution in Nepal. Nepalese Horticulture, J. Nepalese Hort. Soc. 1:30-39. 